\title{
Impact of Migration on the Livelihoods of Tribes People
}

\author{
V. V. Mano Sandesh*, A. Anil Kumar and K. P. Smitha \\ College of Agriculture, Kerala Agricultural University, Kerala, India \\ *Corresponding author
}

Keywords

Migration,

Human Capital,

Alcoholism,

Addictive behavior

Article Info

Accepted:

15 October 2020

Available Online:

10 November 2020

\section{A B S T R A C T}

Migration had a significant impact on the livelihood of tribes people. This had also affected the existing agriculture situation of tribal areas. The study revealed that more than half of the tribal migrants had high livelihood capital index after migration. Immense increase in physical capital of tribes people due to migration was obvious from study results. This caused a temptation for migration among tribal non migrants. After migration majority of tribal migrants had only low natural capital. This tremendous decrease in natural capital indicates poor use of natural resources by tribes people. Globalisation has also affected the life style, food habits and education of tribes people. Cultural changes were observed among the young tribes people and many of them have turned to non agricultural labour activities. This also helped them to achieve higher financial capital and there by increased livelihood capital index.

\section{Introduction}

The global tribal population of approximately 300 million people is composed of about 5,000 distinct tribal cultures worldwide, living in every climate from the Arctic Circle to the tropical rain forests. The highest tribal population of Kerala, an Indian state, is found in Wayanad district. Wayanad is situated in an elevated mountainous plateau on the crust of Western Ghats at a height between 700 and 2100 meters above sea level. Wayanad has a long history of agriculture. Two tribes, who are among the inhabitants of this region from early times, and associated with earliest cultivation of rice in valley wetlands and rainfed millets in uplands, largely by shifting cultivation, are the Kurichian and the Kuruman (Prasanth, 2016). The agro ecological conditions of the area, vastly different from the plains and virtual isolation of the area from the plains due to lack of proper communication and other factors restraining early migration from the plains, the agrobiodiversity conserved and used by the native tribes eventually evolved many landraces of rice and other crops unique to the region (Das and Das, 2014). Later huge migration from plains and domination of these migrants in influencing the cropping pattern in the upland led to the total decline of millets and rise of plantation crops. An employment culture entirely based on the existing forest ecosystem limits the scope for 
adjustment to requirements of new job prospects (Vinayakam and Sekar, 2013). Yet their competency in traditional art and artisans need to be appreciated. Their spread mats, and similar household items were very popular. But now the raw materials are not easily available as access to deep forest is restricted. forest resources like honey, bamboo products, forest medicines have been restricted to Kattunaikan tribal community. This legal restriction has led to poverty. Also labour demand especially that of women in paddy fields, has decreased, as the paddy cultivation has shrunk. The shift to cash crop cultivation like banana, ginger etc. in paddy fields has not improved their condition any better. Migration from one area to another in search of improved livelihoods is a key feature of human history (Dugbazah, 2008 and Mahapatro, 2010). Migration is today a worldwide phenomenon and has become an important issue in our times. (Kishore and Kiran, 2013) Migration has been both a boon and a curse to humans particularly the tribal people (Sundari, 2007). Migration is necessarily a pre-empt move; it is the survival instinct that drives humans to seek better prospects (Anh, 1999). The possible causes of migration can be identified as economic reasons such as dense population and lack of means of livelihood, facility of transport, attraction of industrial centers, facility of trade and commerce. Social reasons such as access to healthcare, education, housing etc, change in social status, change in occupation status (Gowda and Shivashankar, 2007). Physical factors like facility of irrigation, availability of forest/ mineral resources, availability of new land for agriculture purposes and Political factors like wars, society tensions, ethnic/ caste clashes (Martin, 2004 and Rozelle et al., 1999). Due to many reasons like lack of employment, low job opportunities, marriage, food security, health issues, education etc many tribes people are migrating from their native places to various parts of the country (Bagchi and Majumdar, 2010). This study attempts to evaluate the changes in the livelihood of tribes people and agriculture system of the district due to tribal labor migration.

\section{Materials and Methods}

\section{Locale of the study}

The study was conducted in Wayanad district of Kerala state in India. This district has been purposively selected for conducting the study because this is one of the districts in Kerala having the highest concentration of tribes people with migratory nature.

\section{Selection of sample}

The study was conducted in all the four blocks in Wayanad district namely, Mananthavady, Sulthan Bathery, Kalpetta and Panamaram From each block 30 tribal migrants, 10 tribal non migrants and 10 non tribal significant other respondents was selected randomly for the study. Thus total 120 tribal migrants, 40 tribal non migrants and 40 non tribal respondents was the sample size.

\section{Livelihood analysis of tribes people}

In this study the Sustainable livelihood framework of FAO (2008) was used. There are five capital components included under sustainable livelihood framework of FAO. They are Human capital, Physical capital, Financial capital, Social capital and Natural capital.

Under each capital a number of sub variables were identified. Along with that, the variables such as food habits, livestock possession, material possession and expenditure pattern were included under different capitals to enrich the present study. 
Based on the five livelihood capital components described above viz. Human capital, Physical capital, Social capital, Natural capital and Financial capital, their indices will be derived. It is necessary to compute different component capital indices for the measurement of livelihood capital index. The procedure for computing these indices are detailed below.

In order to compute the component capital indices, the components under each capital will be standardized. Except financial capital, the component capitals will be standardized using the following formula.

$Y i=\frac{y i \max -y i}{y i \max -y i \min }$

Where,

$y_{i}=$ observation for the $i^{\text {th }}$ variable of the component capital $(i=1,2, \ldots . . n)$

$\mathrm{y}_{\mathrm{imax}}=$ maximum value that the variable $\mathrm{y}_{\mathrm{i}}$ can attain.

$\mathrm{y}_{\mathrm{imin}}=$ minimum value that the variable $\mathrm{y}_{\mathrm{i}}$ can attain.

Standardisation of financial capital components is done in a different way considering the limitations in fixing maximum attainable values for the financial capital components, unlike the other capital components. For this financial capital is taken as the standardization value of the actual annual family income of the respondent, which is given by the following formula.

Financial capital $=\frac{y-y d}{y \min } \times 10$

Where,

$\mathrm{Y}=$ actual annual family income (y) of the respondent.
$\mathrm{Y}_{\mathrm{d}}=$ annual interest on the total debt the respondent is liable to pay.

$y_{\min }=$ minimum income required for meeting the essential needs of the family.

After standardization, the indices are calculated using the following formula.

$y=100-\left[1 / n \sum_{i=1}^{n} y i \times 100\right]$

Where,

$\mathrm{n}$ is the number of sub components under each capital.

$Y_{i}$ is the standardized value of each capital

Livelihood Capital index is obtained as the average of five capital indices thus obtained.

\section{Results and Discussion}

\section{Livelihood of tribal migrants after migration}

Migration had a significant effect on the livelihood of tribes people. The economic backwardness of tribes people pushed them for migration on a large scale. The scenario analysis of Wayanad district also reveals that a shift in rice cultivation with banana cultivation lowered the labour requirement which affected the adequacy of work and decreased opportunity of tribal agricultural labourers. Since tribal agricultural labourers were unskilled labourers they were not able to shift their labour hood towards skilled works. So they were forced to do agriculture labour work where ever it was available. Places like Coorg, Kudak etc. of Karnataka state were on border side of Wayanad district, provided amble opportunity for tribes people for agricultural work. Continuous work opportunity acted as a major pill factor for 
migration of tribes people. The economic capital of migrating tribes was enhanced and thus tribes started believing that their livelihood can be increased through migration. But later it affected all other five capital components of livelihood of tribes people. The present livelihood capitals of tribal migrants after migration were detailed below.

\section{Human capital}

From Table 1, it was clear that 73.33 per cent of the tribal migrants possess a medium level of human capital and only 7.50 per cent had a high human capital. But this was noted that only 19.16 per cent of the tribespeople had low level of human capital which shows an increase in human capital after migration.

\section{Physical capital}

Immense increase in physical capital of tribes people due to migration was obvious from the Table 2. There was an increase in physical capital index of tribes people from 32.74 to 63.34. Owing to this doubling of physical capital there were no indeed tribal migrants coming under low physical capital. This hike in physical capital shows the positive impact of government interventions on the livelihood of tribes people. Also it was revealed that physical capital was noticeably increased for tribes belonging to Kattunaikan and Paniya communities.

\section{Social capital}

Results in Table 3 shows that 85.83 per cent of tribal migrants had a medium social capital and only 1.66 per cent had a high social capital after migration. This shows a decrease in social capital due to migration because 5 per cent of tribes people had a high social capital before migration which was reduced to 1.66 per cent after migration

\section{Natural capital}

Looking to data in Table 4, 83.33 per cent of tribal migrants had low utilisation of natural resources. But before migration 45.83 per cent had medium natural capital. This decrease in utilisation of natural resources was a significant effect of migration of tribes people. Previously they depended on forest for minor forest products like fire wood, honey, medicines etc. But now a day they had gas connection in houses which reduced fire wood use in their household.

\section{Financial capital}

Table 5 shows that majority of the respondents that is 68.33 per cent had a medium financial capital before migration. But there was a remarkable change in the financial capital after migration and 70.83 per cent of tribes people came under high financial capital category.

\section{Classification of tribal migrants based on livelihood capital index before and after migration}

More than half $(60.83 \%)$ of the tribal migrants had high livelihood capital index after migration. This exaltation of livelihood of tribes people was a positive sign of better life of tribes people after migration. Even if there was increment in the livelihood, some consequential effects were also observed in the life of tribes people due to migration.

The major one was the magnification of addictive behavior of tribes people. Necessary actions are inevitable to mitigate this issue. Also there were issues of increased stress and health problems faced by the tribal migrants. Misuse of illiterate tribal women at migratory places and even during transport was also reported. 
Most of the cases were not revealed to the concerned authority by the tribes people due to fear or lack of awareness. Proper extension activities are necessary to tackle such issues. Open discussion and proper actions can be effective in reducing such issues in future.

Contribution of various components capitals to the livelihood capital index after migration

Regarding the contribution of component capitals before migration, physical capital is rated as the component which is contributing to the highest to the livelihood capital index. The second highest contribution to the livelihood capital index is by human capital. These two capital components together contribute 52.41 percentage to the livelihood capital after migration. It was also revealed from the Table 7 that the variation of human capital is much higher than physical capital. This shows that the material possession, land possession, type of house, electrification etc had almost similarity among the tribal communities.

The step back of human capital from first position to second position after migration was due to the increased addictive behavior among the tribes people. The third highest contributor to the livelihood capital index was social capital followed by physical capital. The difference in contributions of human capital and social capital to the livelihood capital index is meager. Natural capital was the least contributor among the five capital components of livelihood capital index after migration.

\section{Relationship between profile characteristics and livelihood capital index of tribal migrants before and after migration}

Pearson's Correlation Coefficient given in Table 6 shows that age, annual income, education, land holding, experience in agriculture and level of aspiration had a high significant correlation with human capital. The correlation was negative incase of age and experience in agriculture with human capital. Interestingly marital status and wage per day were having significant correlation with human capital, lose its significance after migration with human capital.

\section{Livelihood of tribes people after migration}

\section{Human capital}

A decrease in human capital was observed among the tribal migrants after migration. There was a decrease in human capital by 3.28 index value. Most of the tribal migrants had a medium human capital. After migration there was a hike in the number of literate tribes people. Due to several Government schemes and interventions number of hospitals and road facilities were increased. This enhanced the accessibility of tribes people to hospitals and thereby increase in frequency of visiting hospitals. Migration doesn't make a positive impact on the hygiene of tribes people rather, there was decrease in hygiene especially for male tribal migrants. Food habits of tribes have been changed a lot due to migration. This was evident from the data regarding the diet they follow after migration.

A prime factor revealed from the study was that there was lofty increase in the addictive behavior of tribes people due to migration. Due to this reason the increase in education and health status was not much reflected on the human capital of tribes people and cause a reduction in human capital index. Continuous awareness programs and thorough inspections are necessary to reduce the addictive behavior of tribes people. More case studies were reported from tribal area regarding the suicide of tribal migrants due to problems aroused as a result of addictive behavior. 
Table.1 Distribution of respondents based on human capital before and after migration

\begin{tabular}{|l|l|c|c|c|c|}
\hline SI. No. & Category & \multicolumn{2}{|c|}{ Before migration } & \multicolumn{2}{|c|}{ After migration } \\
\cline { 3 - 6 } & & Frequency & Percentage & Frequency & Percentage \\
\hline 1. & Low & 22 & 18.33 & 23 & 19.16 \\
\hline 2. & Medium & 73 & 60.83 & 88 & 73.33 \\
\hline 3. & High & 25 & 20.83 & 9 & 7.50 \\
\hline
\end{tabular}

Table.2 Distribution of respondents based on physical capital before and after migration

\begin{tabular}{|l|l|c|c|c|c|}
\hline \multirow{2}{*}{ SI. No. } & \multirow{2}{*}{ Category } & \multicolumn{2}{|c|}{ Before migration } & \multicolumn{2}{|c|}{ After migration } \\
\cline { 3 - 6 } & & Frequency & Percentage & Frequency & Percentage \\
\hline 1. & Low & 74 & 61.66 & 0 & 0.00 \\
\hline 2. & Medium & 46 & 38.33 & 31 & 25.83 \\
\hline 3. & High & 0 & 0.00 & 89 & 74.16 \\
\hline
\end{tabular}

Table.3 Distribution of respondents based on social capital before and after migration

\begin{tabular}{|l|l|c|c|c|c|}
\hline Sl. No. & \multirow{2}{*}{ Category } & \multicolumn{2}{|c|}{ Before migration } & \multicolumn{2}{|c|}{ After migration } \\
\cline { 3 - 6 } & & Frequency & Percentage & Frequency & Percentage \\
\hline 1. & Low & 5 & 4.16 & 15 & 12.50 \\
\hline 2. & Medium & 109 & 90.83 & 103 & 85.83 \\
\hline 3. & High & 6 & 5.00 & 2 & 1.66 \\
\hline
\end{tabular}

Table.4 Distribution of respondents based on natural capital before and after migration

\begin{tabular}{|l|l|c|c|c|c|}
\hline \multirow{2}{*}{ S. No. } & \multirow{2}{*}{ Category } & \multicolumn{2}{|c|}{ Before migration } & \multicolumn{2}{|c|}{ After migration } \\
\cline { 3 - 6 } & & Frequency & Percentage & Frequency & Percentage \\
\hline 1. & Low & 21 & 17.50 & 100 & 83.33 \\
\hline 2. & Medium & 55 & 45.83 & 14 & 11.66 \\
\hline 3. & High & 44 & 36.66 & 6 & 5.00 \\
\hline
\end{tabular}

Table.5 Distribution of respondents based on financial capital before and after migration

\begin{tabular}{|l|l|c|c|c|c|}
\hline S1. No. & \multirow{2}{*}{ Category } & \multicolumn{2}{|c|}{ Before migration } & \multicolumn{2}{|c|}{ After migration } \\
\cline { 3 - 6 } & & Frequency & Percentage & Frequency & Percentage \\
\hline 1. & Low & 36 & 30.00 & 5 & 4.16 \\
\hline 2. & Medium & 82 & 68.33 & 30 & 25.00 \\
\hline 3. & High & 2 & 1.66 & 85 & 70.83 \\
\hline
\end{tabular}


Table.6 Distribution of respondents based on livelihood capital index before and after migration

\begin{tabular}{|l|l|c|c|c|c|}
\hline \multirow{2}{*}{ SI. No. } & \multirow{2}{*}{ Category } & \multicolumn{2}{|c|}{ Before migration } & \multicolumn{2}{|c|}{ After migration } \\
\cline { 3 - 6 } & & Frequency & Percentage & Frequency & Percentage \\
\hline 1. & Low & 31 & 25.83 & 5 & 4.16 \\
\hline 2. & Medium & 60 & 50.00 & 42 & 35.00 \\
\hline 3. & High & 29 & 24.16 & 73 & 60.83 \\
\hline
\end{tabular}

Table.7 Percentage contribution of various capital components to the livelihood capital index after migration

\begin{tabular}{|c|c|c|c|c|c|}
\hline $\begin{array}{l}\text { Sl. } \\
\text { No. }\end{array}$ & Capitals & Index value & $\mathrm{CV}$ & $\begin{array}{c}\% \text { Contribution } \\
\text { to LI }\end{array}$ & Rank \\
\hline 1. & Human & 51.77 & 25.57 & 23.57 & II \\
\hline 2. & Physical & 63.34 & 12.34 & 28.84 & I \\
\hline 3. & Social & 49.85 & 9.66 & 22.70 & III \\
\hline 4. & Natural & \multicolumn{2}{|r|}{38.34} & 3.58 & V \\
\hline 5. & Financial & 46.78 & 23.88 & 21.30 & IV \\
\hline & Livelihood & 43.92 & 11.27 & & \\
\hline
\end{tabular}

Table.8 Correlation between profile characteristics and livelihood index

\begin{tabular}{|l|l|c|c|}
\hline $\begin{array}{l}\text { Sl. } \\
\text { no }\end{array}$ & Independent variables & $\begin{array}{c}\text { Livelihood } \\
\text { Capital Index } \\
\text { before } \\
\text { migration }\end{array}$ & $\begin{array}{c}\text { Livelihood } \\
\text { Capital Index } \\
\text { after migration }\end{array}$ \\
\hline $\mathbf{1}$ & Age & $-0.507^{* *}$ & $-0.284^{* *}$ \\
\hline $\mathbf{2}$ & Family members & 0.111 & 0.093 \\
\hline $\mathbf{3}$ & Marital status & $-0.401^{* *}$ & -0.038 \\
\hline $\mathbf{4}$ & Annual income & $0.285^{* *}$ & $0.296^{* *}$ \\
\hline $\mathbf{5}$ & Education & $0.449^{*} *$ & $0.311^{*}$ \\
\hline $\mathbf{6}$ & Land holding & $0.290^{* *}$ & $0.275^{* *}$ \\
\hline $\mathbf{7}$ & Wage per day & $0.297^{* *}$ & 0.026 \\
\hline $\mathbf{8}$ & Political orientation & $0.183^{*}$ & -0.005 \\
\hline $\mathbf{9}$ & Debt & -0.068 & -0.018 \\
\hline $\mathbf{1 0}$ & Experience in agriculture & $-0.506^{* *}$ & $-0.275^{* *}$ \\
\hline $\mathbf{1 1}$ & Type of house & 0.164 & 0.175 \\
\hline $\mathbf{1 2}$ & Level of aspiration & $0.401^{* *}$ & $0.242^{* *}$ \\
\hline $\mathbf{1 3}$ & Economic motivation & $0.316^{* *}$ & $0.198^{*}$ \\
\hline $\mathbf{1 4}$ & Self confidence & 0.090 & -0.102 \\
\hline $\mathbf{1 5}$ & Traditional value orientation & -0.039 & -0.110 \\
\hline $\mathbf{1 6}$ & Risk preference & 0.040 & -0.106 \\
\hline & & & \\
\hline
\end{tabular}


A special attention is needed in these issues. Joint management of these issues by local people and officials will be more effective in controlling the addictive behavior of tribes people.

\section{Physical capital}

Among the five livelihood capital components, physical capital was the most observable capital component. As there was an increase in the physical capital of migrating tribes people, it caused a temptation for migration among tribal non migrants. This has increased migration proneness of tribes people. An advantage of tribal migrants was that they reside exterior to the forest for the easiness of migration and thus they became beneficiaries of many government programs.

\section{Social capital}

A substantial number of tribal migrants had medium social capital after migration. There was a decerease in the social capital index value from 52.49 to 49.85 after migration. This decrease in the social capital was an indication that tribal migrants were not actively involving in the social activities. This may cause disinclination of tribal migrants with the social issues. A heartening factor was that migration doesn't affect the social relation considerably. Government and nongover1nmental organizations should take initiatives to enhance the social capital of tribal migrants.

\section{Natural capital}

Before migration majority of the tribal migrants were having medium natural capital whereas after migration a lion share of tribal migrants had only low natural capital. This tremendous decrease in natural capital stipulates poor use of natural resources by tribes people. Being agricultural labourers tribes people had less interest in crop cultivation and most of tribal migrants had no land area for cultivation. Many tribes especially Kattunaikans discontinued honey collection after migration. Many of the tribal families shifted their home from interior forest to exterior forest which also caused a decrease in their dependency of natural resources. Young tribal migrants were not interested in the traditional ways of living rather they were enthusiastic on modern lifestyle. This change in attitude was not predominant among tribes but was noticed. This change in attitude shows that in future they might depend forest even less when compare to present situation. As a part of globalization, deprivation in the traditional ways of life was observable in the lifestyle of tribal migrants.

\section{Financial capital}

70.83 per cent of the tribal migrants had a high financial capital and only 4.16 per cent of tribal migrants had low financial capital after migration. This is very positive sign that tribes people started earning a higher annual income and they started saving money for various purposes. It doesn't mean that all the tribal migrants had saving habit rather there was a change observed in the number of tribal migrants having bank account. There was decrease in the number of tribal migrants having debt and this indicates that migration helped them to mitigate their debt. Some of the tribal migrants were able to send their children to school and colleges which is a positive sign of higher financial capital. Many of them became land owners and built their own home with the support of government and other agencies. Individual annual income was increased almost double due to increase in the working days. Even though there were still need of some necessary actions to circumvent low wage structure and gender inequality in wages at migratory places. 
Classification of tribal migrants based on livelihood capital index before and after migration

This study gives a light on the fact that there was an increase in the livelihood capital index of tribes people from 37.95 to 43.92 . This enhancement in the livelihood capital index was not only due to migration but also due to the developmental activities of government carried out in the past years. Policy makers, planners, administrators and academicians need to consider the decline in human capital and natural capital and importance of social capital and physical capital while strategising and formulating development paradigms and welfare measures.

\section{Contribution of various components capitals to the livelihood capital index after migration}

Before migration human capital was the largest contributor to the livelihood index of tribes people. But after migration physical capital became the largest contributor. This implies that the physical assets of tribes people has been increased due to migration. Even though there was an increase in the financial capital, it was not that much reflected on the contribution to the livelihood capital index. A significant decline in the contribution of natural capital was observed from the Table which shows a change in the traditional lifestyle of tribes people. This study makes us aware of the changes in the capital components made on the livelihood of tribes people due to migration.

\section{Relationship between profile characteristics and livelihood capital index of tribal migrants before and after migration}

It was found that age had a negative correlation with the livelihood capital index of tribes people before migration. As age increased, the working ability of tribes people also decreased and their by their livelihood capital index also declined. Shrinkage of financial capital causes a decline in the human capital components like health seeking behavior, food habits etc. It was also take cognizance that the habit of collecting minor forest produce like fuel wood, honey, medicine, lac etc further down due to poor health of old tribal migrants. As age increased tribes people liked to settle in their hamlet rather than roaming for job. This decrease in migratory behaviour also caused a decline in the livelihood capital index.

It was clear that marital status and livelihood capital index were negatively correlated before migration. The reason was that when there was an increase in the number of family members through marriage, there was increase in expenses like education, food, clothing etc which will affect the financial capital. A positive correlation was observed between annual income and livelihood capital index of tries people before as well as after migration. As the annual income increased, naturally the financial capital and physical capital increased tremendously. Education was found to have a positive correlation with the livelihood capital index before and after migration. Those tribes who were having relatively higher education especially from Kurichya and Paniya community were found to have better livelihood even before and after migration. Education made tribes people capable of getting better job opportunity even in the migratory places and such tribes people had good social participation. Those tribes who were having a higher land holding possessed a better livelihood capital index even before and after migration (Table 8).

Tribes people who were land owners, were able to produce a better income from their own land area and thereby the migratory nature was found to be less. Among migratory tribes the land holding was not prominent. 
But among Kurichya land holding was higher and their livelihood was found to be relatively inflated. Among most of the migratory tribes who were from Kattunaika and Paniya community, the size of land holding was less.

The study revealed that more than half of the tribal migrants had high livelihood capital index after migration. Immense increase in physical capital of tribes people due to migration was obvious from study results and it was remarkable for tribes belonging to Kattunaikan and Paniya communities. This caused a temptation for migration among tribal non migrants. After migration majority of tribal migrants had only low natural capital.

This tremendous decrease in natural capital indicates poor use of natural resources by tribes people. Sixty five per cent of the tribal non migrants had high livelihood capital index. Globalisation has also affected the life style, food habits and education of tribes people. Cultural changes were observed among the young tribes people and many of them have turned to non agricultural labour activities. This also helped them to achieve higher financial capital and there by increased livelihood capital index. Scarcity of agricultural labourers was the major consequence of tribal labour migration, which in turn caused a decrease in agricultural land area.

\section{References}

Anh, D. N. 1999. Market Reforms and Internal labour Migration in Vietnam. Asian \& Pac migration J. 8 (3): 381407.

Babu, A., 2018. State response towards human rights violations among Adivasis in Wayanad District.

Bagchi, K.K. and S. Majumdar.2010. Dynamics of Out-Migration of
Agricultural Labourers: A Micro-Level Study in Two Districts Of West Bengal. Agric. Econ. Res. Rev. 24: 568-575

Das, S. and Das, M. 2014. Income, Migration $\&$ Social Adjustment of the Tribal People in Tripura: A case study of 'Tripuri' tribe. J. Space and Culture, India, 2(1): 5-13

de Haan, A. (2000) Migrants, Livelihoods, and Rights: The Relevance of Migration in Development Policies. Social Development Working Paper 4. London: DFID.

Deshingkar, P., 2010. Migration, remote rural areas and chronic poverty in India. ODI.

Deshingkar, P., and Start, D. (2003) Seasonal Migration for Livelihoods in India: Coping, Accumulation and Exclusion. Working Paper. 220 Pp. London: ODI.

Dugbazah, J. E. 2008. Gender, Migration and Rural livelihoods in Ghana: A Case of the Ho District. Unpub. PhD. Thesis, The University of Birmingham, United Kingdom, $32 \mathrm{p}$.

FAO. 2008. The livelihood assessment toolkit: Analysing and responding to the impact of disasters on the livelihoods of people. Food and Agriculture Organisation of the United Nations, Rome. pp. 28-49.

Gowda, S. and Shivashankar, G. P. 2007. Rural Migration to the Indian Metropolis: Case Study Banglore. ITPI J. 4(1): 67-69

Kishore, K. and Kiran, V. 2013. Labour Migration - A Journey from Rural To Urban. J. Business Manag. \& Social Sci. Res. 2(5): 61-66

Llewelyn, S. (2005) 'Globalization and Labour Migration in Betul district, Madhya Pradesh: A Case Study'. IndoCanadian Shastri Applied Research Project (SHARP). New Delhi: Jawaharlal Nehru University.

Lolaksha Nagaveni, P. and Anand, A., 2017. 
Migration and Poverty: An Indian Reality. Social Action, 67(1), pp. 32-50.

Mahapatro, S. R. 2010. Patterns and determinants of female migration in India: Insights from census. Institute for Social and Economic Change, Banglore,pp.13-16

Martin, S.F., 2004. Refugee women. Lexington books. Pp. 108-147

Moosan, H., Stanley, A., Vijayakumar, K., Jayasree, A.K., Lawrence, T. and Veena, A., 2019. Impediments to optimal health-care utilization of a particularly vulnerable tribal group in Wayanad: a qualitative study. Indian journal of community medicine: official publication of Indian Association of Preventive \& Social Medicine, 44 (Suppl 1), p.S62.

Narain, U., S. Gupta and K. van 't. Veld (2005) Poverty and the Environment: Exploring the Relationship between Household Incomes, Private Assets, and Natural Assets. Working Paper 134. New Delhi: Centre for Development Economics, Department of Economics, Delhi School of Economics.

Oraon, V., 2012. Changing Pattern of Tribal Livelihoods: A Case Study in Sundargarh District, Odisha (Doctoral dissertation).

Prasanth, P. 2016. A Peep in to the Tribal Problems of Wayanad with Special
Reference to Kattunayakas. IJIR J. 2(6): 539-543.

Rogaly B. and D. Coppard (2003) 'They Used to Go to Eat, Now They Go to Earn: The Changing Meanings of Seasonal Migration from Puruliya District in West Bengal'. Journal of Agrarian Change 3(3): 395-433.

Rozelle, S., Taylor, J. E. and Brauw, A. De. 1999. Migration, Remittances and Agricultural productivity in China. American Econ. Rev. 89 (2): 287-291

Sadath, A., Jose, K., Meethal, S.T., Mathai, J.K., Venugopal, A.P. and Xavier, N., 2019. Factors associated with alcohol misuse among indigenous tribal men in Wayanad: A qualitative study. Indian journal of psychological medicine, 41(6), pp.516-522.

Speranza, C.I., Wiesmann, U. and Rist, S., 2014. An indicator framework for assessing livelihood resilience in the context of social-ecological dynamics. Global Environmental Change, 28, pp.109-119.

Sundari, S., 2007. Migrant women and urban labour market: Concepts and case studies of problems, gains, and losses. Deep and Deep Publications.

Vinayakam, K. and Sekar, S.P. 2013. Rural To Urban Migration in Indian Metroplis: Case Study Chennai City. J. Humanities \& Social Sci. 6(3): 32-35.

\section{How to cite this article:}

Mano Sandesh, V. V., A. Anil Kumar and Smitha, K. P. 2020. Impact of Migration on the Livelihoods of Tribes People. Int.J.Curr.Microbiol.App.Sci. 9(11): 3720-3730. doi: https://doi.org/10.20546/ijcmas.2020.911.446 